nucleobase and the phosphate linker - to produce nucleic acid analogues with very different properties. Metal-containing variants have also been made, in which the two strands of the double helix are held together by metal-ligand coordination rather than hydrogen bonding.

Now, James Tucker and co-workers at the University of Birmingham, UK, have taken the first steps towards making a DNA mimic in which metals form an integral part of the polymer backbone. On recognizing that the distance between the two cyclopentadienyl $(\mathrm{Cp})$ rings in ferrocene is very similar to the distance between adjacent sets of stacked base pairs in B-DNA, the team set about designing and making a nucleic acid analogue based on this well-known organometallic compound. The resulting ferrocene nucleic acid (FcNA) structure is made up of a repeating $\mathrm{C}_{3}$-linker-ferrocene- $\mathrm{C}_{3}$-linker-phosphate unit, with one nucleobase connected to each of the Cp rings. Starting from a ferrocene monomer functionalized with coupling groups that are compatible with solid-phase synthesis methods, an oligomer comprising 8 ferrocene groups - and hence 16 thymine nucleobases - was made using an automated nucleic acid synthesizer.

Following purification by reversed-phase HPLC, the FCNA oligomer was characterized using a range of techniques including mass spectrometry and cyclic voltammetry. Future work will undoubtedly look at the binding properties of FcNA oligomers to determine whether they can form duplexes (or complexes of some sort) with other nucleic acids. Moreover, the well-characterized electrochemical behaviour exhibited by ferrocene may prove to be a useful addition to the properties usually associated with nucleic acid structures.

\section{RENEWABLE FUELS}

\section{Catalytic upgrade}

Nature 491, 235-239 (2012).

Dwindling resources of crude oil and its increasing price, in addition to the threat of climate change, have all resulted in a greater focus on renewable fuels - particularly biofuels, which are the result of biological carbon fixation. The most common biofuels produced are ethanol and butanol, but these can be difficult to integrate into the existing fuel-use infrastructure. Also, although biological production of higher hydrocarbons has been demonstrated, these routes tend to suffer from poor yields and titres (the amount of fuel produced per volume of fermentation broth). Now, Dean Toste and co-workers from the University of California, Berkeley,

have proposed a chemical method that could be used to upgrade more common and higher-yielding fermentation products into a mixture containing the desired hydrocarbons.
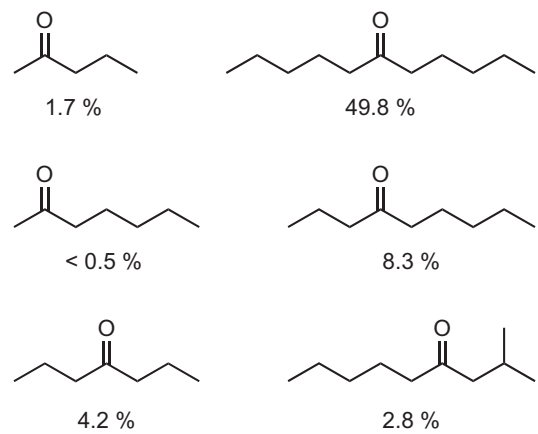

Clostridium acetobutylicum is a bacterium that has been known for almost 100 years, and it produces, by fermentation, a mixture of acetone, butanol and ethanol (widely known as $\mathrm{ABE}$ ). Toste and co-workers recognized that this classic mixture of two-, threeand four-carbon products harbour both electrophilic and nucleophilic carbon atoms such that a suitable chemical process might enable conversion to higher hydrocarbons. The reactions involved are relatively simple - a combination of transition-metalcatalysed dehydrogenation of the alcohols, base-catalysed aldol reactions, dehydration and a final reduction result in a formal alkylation of the acetone. The key, however, is to optimize the process to avoid the multitude of possible side reactions and obtain depending on the reaction conditions linear ketones with between five and eleven carbon atoms (pictured).

Development of these reaction conditions into a process to produce various hydrocarbon fuels also requires integration with the fermentation system. Here, Toste and co-workers have designed a two-phase liquid-extraction system that allows the $\mathrm{ABE}$ products to be easily separated from the fermentation broth for direct input into the catalytic upgrade system. The overall process converts up to $58 \%$ of the carbon in glucose into ketones. A final step in the process will be the integration with established procedures for the deoxygenation of the ketones.

Written by Stuart Cantrill, Stephen Davey and Russell Johnson.

\section{Correction}

In the version of the Research Highlight 'Materials chemistry: Compliant crystals' originally published (Nature Chem. 4, 866; 2012), the wrong affiliation was given. Corrected after print 23 October 2012

\section{blog $_{\text {roll }}$ i}

\section{Eye of the beholder}

From pesky biochemists winning the Nobel Prize in Chemistry, to the social construction of scientific ideas. Is it all just a matter of perspective?

Considering the time of year, it would be rude not to mention this year's Nobel Laureates in Chemistry, Robert J. Lefkowitz and Brian K. Kobilka. Being awarded the prize "for studies of G-protein-coupled receptors" resulted in a tedious furore owing to the awarding of the prize to biochemists. The usual heavyweights of the blogosphere have done their part deriding these banalities, though I particularly enjoyed John's article at 'It's The Rheo Thing', highlighting the 'impurity' of two of the world's leading 'chemistry' journals (http://go.nature.com/qqHOd4).

The role of society in science, although not a new concept (I would say one as old as science itself), is one that is increasingly developing in importance. For example, society's perception of genetically modified food has had widespread consequences for its development, production and distribution worldwide. Two pieces relating to this boiling pot of anguish have recently caught my attention, one by science-policy academic Jack Stilgoe of Responsible Innovation who in response to an article on the Rothamsted protests highlights the dangers of unstructured and polarized debate on such ethical dynamite (http://go.nature. $\mathrm{com} / \mathrm{pPcOmP}$ ); and a second by Michael Eisen of 'it is NOT junk' challenging the basis of "Proposition 37, which would require the labeling of genetically modified foods" in the USA (http://go.nature.com/Y7qWst).

Finally, academic Alice Bell, of 'through the looking glass', writes an intriguing piece on the social construction of science (http:// go.nature.com/AzaEby), challenging the perception (presumably of 'scientists') that describing science as a social construct is negative. Bell writes "Saying science is a social construction does not amount to saying science is make believe" and continues to discuss the 'social construction' of St Paul's, CERN and scientific ideas.

Written by Karl D. Collins who blogs at http://karldcollins.wordpress.com 